\title{
High-Pressure Raman Spectroscopy and X-ray Diffraction Study on Scottyite, $\mathrm{BaCu}_{2} \mathrm{Si}_{2} \mathrm{O}_{7}$
}

\author{
Pei-Lun Lee ${ }^{1, *}$, Eugene Huang ${ }^{2,3}$ and Jennifer Kung ${ }^{4, *}$ \\ 1 Department of E-Learning Design and Management, National Chiayi University, Chiayi 621302, Taiwan \\ 2 Center for High Pressure Science \& Technology Advanced Research, Shanghai 201203, China; \\ eugenekohan@gmail.com \\ 3 Guanghua Institute of Gemmology and Mineral Resources, Jiangxi University of Applied Sciences, \\ Nanchang 330100, China \\ 4 Department of Earth Sciences, National Cheng-Kung University, Tainan 70101, Taiwan \\ * Correspondence: peilun@mail.ncyu.edu.tw (P.-L.L.); jkung@mail.ncku.edu.tw (J.K.); \\ Tel.: +886-5-2263411 (ext. 1521) (P.-L.L.); +886-6-2757575 (ext. 65434) (J.K.)
}

check for updates

Citation: Lee, P.-L.; Huang, E.; Kung, J. High-Pressure Raman Spectroscopy and X-ray Diffraction Study on Scottyite, $\mathrm{BaCu}_{2} \mathrm{Si}_{2} \mathrm{O}_{7}$. Minerals 2021, 11, 608. https://doi.org/10.3390/ $\min 11060608$

Academic Editors: Anna Pakhomova and Ilya Kupenko

Received: 29 April 2021

Accepted: 3 June 2021

Published: 7 June 2021

Publisher's Note: MDPI stays neutral with regard to jurisdictional claims in published maps and institutional affiliations.

Copyright: (c) 2021 by the authors. Licensee MDPI, Basel, Switzerland. This article is an open access article distributed under the terms and conditions of the Creative Commons Attribution (CC BY) license (https:// creativecommons.org/licenses/by/ $4.0 /)$.

\begin{abstract}
In situ high-pressure synchrotron X-ray diffraction and Raman spectroscopic experiments of scottyite, $\mathrm{BaCu}_{2} \mathrm{Si}_{2} \mathrm{O}_{7}$, were carried out in a diamond anvil cell up to $21 \mathrm{GPa}$ at room temperature. X-ray diffraction patterns reveal four new peaks near 3.5, 3.1, 2.6 and $2.2 \AA$ above $8 \mathrm{GPa}$, while some peaks of the original phase disappear above $10 \mathrm{GPa}$. In the Raman experiment, we observed two discontinuities in $d v / d P$, the slopes of Raman wavenumber $(v)$ of some vibration modes versus pressure $(P)$, at approximately 8 and $12 \mathrm{GPa}$, indicating that the Si-O symmetrical and asymmetrical vibration modes change with pressure. Fitting the compression data to Birch-Murnaghan equation yields a bulk modulus of $102 \pm 5 \mathrm{GPa}$ for scottyite, assuming $K_{o}{ }^{\prime}$ is four. Scottyite shows anisotropic compressibility along three crystallographic axes, among which $c$-axis was the most compressible axis, $b$-axis was the last and $a$-axis was similar to the $c$-axis on the compression. Both X-ray and Raman spectroscopic data provide evidences that scottyite undergoes a reversible phase transformation at $8 \mathrm{GPa}$.
\end{abstract}

Keywords: scottyite; high pressure; phase transformation

\section{Introduction}

Rock-forming minerals that occur on the Earth's crust may change structures and physical properties in the mantle environment. Numerous high-pressure experiments in Earth sciences were focused on silicate minerals that are directly relevant to the Earth's interior. Some orthosilicate minerals, such as olivine, show that the $\mathrm{SiO}_{4}$ tetrahedron is relatively rigid; not until pressures as high as $30 \mathrm{GPa}$ do $\mathrm{SiO}_{4}$ tetrahedron start to show signs of distortion. The distortion of $\mathrm{SiO}_{4}$ tetrahedron is interpreted as due to the distortion of Si-O-Si linkage, which was recognized by the kink in the $d v / d P$ (the slopes of Raman wavenumber $(v)$ versus pressure $(P))$ plot [1]. In contrast, before the distortion of $\mathrm{SiO}_{4}$ tetrahedron, the most easily distorted crystal structure took place on the bond connection between cation and $\mathrm{SiO}_{4}$ tetrahedron. Therefore, it would be interesting to look into sorosilicates that have two tetrahedrons shared and linked by one oxygen atom, forming a basic structural unit of $\mathrm{Si}_{2} \mathrm{O}_{7}$. The $\mathrm{SiO}_{4}$ tetrahedron is considered to be a rigid body and not easy to be compressed.

Scottyite, named after Michael M. Scott, is a Ba-Cu sorosilicate, $\mathrm{BaCu}_{2} \mathrm{Si}_{2} \mathrm{O}_{7}$, [2]. As a newly found mineral, scottyite is a very rare mineral, first reported as an unnamed $\mathrm{Ba}-\mathrm{Cu}$ silicate from Eifel, Germany [3-5]. It was then identified as an orthorhombic system with space group Pbnm and unit-cell parameters $a=6.866 \AA, b=13.901 \AA, c=6.902 \AA$, and $\mathrm{V}=625.70 \AA^{3}$ [6]. It was later found in many other localities, including the Wessels mine, Kalahari Manganese Fields, Northern Cape Province, Republic of South Africa, from which 
the unit-cell parameters are determined as $a=6.8556 \AA, b=13.1725 \AA, c=6.8901 \AA$, and $\mathrm{V}=622.21 \AA^{3}$ on the basis of a single-crystal XRD study [2]. The structure of scottyite is based on a tetrahedral framework consisting of $\mathrm{SiO}_{4}$ and $\mathrm{CuO}_{4}$ tetrahedrons. The flattened $\mathrm{CuO}_{4}$ tetrahedrons share corners with one another to form chains parallel to the c-axis. These chains are interlinked by $\mathrm{Si}_{2} \mathrm{O}_{7}$ tetrahedral dimers and $\mathrm{Ba}^{2+}$ cations, which are bonded to seven $\mathrm{O}$ atoms of irregular coordination numbers. Within the $\mathrm{CuO}_{4}$ tetrahedral chain, the $\mathrm{Cu}-\mathrm{O}-\mathrm{Cu}$ angle is $124.49^{\circ}$, which is responsible for the antiferromagnetic coupling in $\mathrm{BaCu}_{2} \mathrm{Si}_{2} \mathrm{O}_{7}$ [2,7-9].

\section{Experimental Method}

\subsection{Raman Spectroscopy}

Small chips of natural scottyite crystal (RRUFF Project, deposition no. R120077, from the Wessels mine, Republic of South Africa) with a dimension of $80 \mu \mathrm{m}$ were used as a starting material in the Raman spectroscopic experiment. In this high pressure work, a disk of T301 stainless steel with a thickness of $250 \mu \mathrm{m}$ was used as a gasket. The gasket was first compressed between the diamond anvils to make an indentation on which a hole of $150 \mu \mathrm{m}$ was then drilled for the sample chamber. The sample was loaded in the chamber using a 4:1 methanol:ethanol mixture as pressure-transmitting medium. It was then gradually compressed to high pressure and then decompressed to room pressure. The ruby fluorescence method was used for pressure measurement [10] after each pressure increment. We measured more than two ruby grains to make sure that the pressure of the compressed sample remained hydrostatic. A Horiba iHR550 unit installed at the Department of Earth Sciences, National Cheng Kung University, was used in the Raman spectroscopic study. A semiconductor laser beam of $458 \mathrm{~nm}$ was used as an excitation source. The laser light of $100 \mathrm{~mW}$ was focused on the sample in the diamond cell, and Raman signals were collected in a back-scattered way by the CCD detector. The recording time of each Raman spectrum was $60 \mathrm{~s}$ (averaged by 3 times of acquisition). During each measurement, pressure was recorded before and after each Raman spectrum was collected. Both compression (loading) and decompression (unloading) processes were conducted.

\subsection{X-ray Diffraction}

Synchrotron X-ray diffraction method was applied to the study of the behaviors of natural scottyite (RRUFF Project, deposition no. R120077, from the Wessels mine, Republic of South Africa) at high pressure. The powder of scottyite was then loaded into the hole (200 $\mu \mathrm{m}$ in diameter) in a T301 stainless steel gasket, prepared in the same way as the high pressure Raman measurement. After the chamber was loaded with the sample, it was then filled with silicon oil as a pressure-transmitting medium, and then gradually compressed to high pressure and decompressed to room pressure. Pressure determination was achieved by observing the shift of the ruby R1 emission line. More than two ruby grains were measured, to make sure that the pressure remained hydrostatic.

The X-ray diffraction (XRD) experiment was carried out at PLS-II 5A beamline at the Pohang Accelerator Laboratory, South Korea. The size of the X-ray beam was confined to $100 \mu \mathrm{m}$ and the position of the beam was adjusted to fall on the center of the sample chamber in each run. Pressure was gradually increased up to about 17 GPa and then decreased relatively rapidly back to the ambient conditions. The scattering data were collected by MAR345 detector and integrated using the FIT2D v10.132 (ESRF) [11]. Lattice parameters were calculated by a least-square method developed by Novak and Colville [12].

\section{Results}

\subsection{Raman Spectroscopy}

The Raman spectra of scottyite are arbitrarily divided into four regions. Region 1 ( $v_{1}$ and $v_{3}$ modes), between 800 and $1100 \mathrm{~cm}^{-1}$, contains bands attributed to the Si-O symmetric and antisymmetric stretching vibrations within the $\mathrm{SiO}_{4}$ tetrahedrons. Region 2, between 660 and $700 \mathrm{~cm}^{-1}$, includes bands resulting from the Si- $\mathrm{O}_{\mathrm{br}}-\mathrm{Si}\left(\mathrm{O}_{\mathrm{br}}\right.$ : bridging $\mathrm{O}$ 
atom) bending vibrations within the $\mathrm{Si}_{2} \mathrm{O}_{7}$ tetrahedral dimers. Region 3 ( $v_{2}$ and $v_{4}$ modes) ranges from 420 to $660 \mathrm{~cm}^{-1}$, and contains modes related to the O-Si-O symmetric and anti-symmetric bending vibrations within the $\mathrm{SiO}_{4}$ tetrahedrons. The bands in Region 4 , below $420 \mathrm{~cm}^{-1}$, are mainly related to $\mathrm{Cu}-\mathrm{O}$ interactions and lattice vibrational modes, as well as the rotational and translational modes of $\mathrm{SiO}_{4}$ tetrahedrons [2].

Table 1 shows the comparison of our results of Raman data of scottyite with the previous investigation at the room pressure. Some of the representative Raman spectra of scottyite were taken during the loading and unloading processes of the experiment in this study (Figure 1). The $v_{1}$ mode $\left(895 \mathrm{~cm}^{-1}\right)$ and $v_{3}$ mode $\left(1016,958\right.$ and $\left.863 \mathrm{~cm}^{-1}\right)$ in Region 1 , Si- $\mathrm{O}_{\mathrm{br}}-\mathrm{Si}$ bending mode $\left(675 \mathrm{~cm}^{-1}\right)$ in Region 2 , and $v_{2}$ mode $\left(458 \mathrm{~cm}^{-1}\right)$ and $v_{4}$ mode $\left(608,579\right.$ and $\left.560 \mathrm{~cm}^{-1}\right)$ in Region 3 are observed at the ambient conditions in this study. From Figures 1 and $2 \mathrm{a}, \mathrm{b}$, the frequencies of most Raman modes are found to increase with increasing pressure, except peak $R_{2}, v_{4}, v_{2}, R_{4 c}, R_{4 f}, R_{4 g}$ and $R_{4 k}$ between 8 and $12 \mathrm{GPa}$. The intensity of most of the peaks becomes weaker with increasing pressure while some Raman bands (such as $R_{2}, v_{4}$ and $v_{2}$ mode) remain quite sharp at all pressures. It is found that the $v_{1}$ mode of scottyite becomes broader, and one distinct peak (new peak) is found on the right shoulder when the pressure exceeds $8 \mathrm{GPa}$, and an additional new peak was found above $12 \mathrm{GPa}$. The intensity of the new peak becomes stronger and shifts to a lower wavenumber with increasing pressure. The $R_{2}$ mode of scottyite remains quite sharp at all pressures, but shifts to lower wavenumber with increasing pressure between 8 and $12 \mathrm{GPa}$. The $v_{3 \mathrm{a}}$ mode of scottyite becomes weaker with increasing pressure between 8 and $12 \mathrm{GPa}$, and disappears above $12 \mathrm{GPa}$. We also found some new peaks on $v_{1}, R_{4 d}$ modes between 8 and $12 \mathrm{GPa}$ and $v_{1}, v_{4}, R_{4 a}, R_{4 c}, R_{4 j}$ modes above $12 \mathrm{GPa}$.

The discontinuities of the linear trend on the $d v / d P$ (Raman modes shift as function of pressure) are also shown in Tables 2 and 3. All the modes of scottyite show discontinuity in the $d v / d P$ slope at $\sim 8 \mathrm{GPa}$, and some modes show additional discontinuity at $12 \mathrm{GPa}$. During the unloading process, all vibrational modes persist until $8 \mathrm{GPa}$ where all modes shift back to the position as the loading process. Below $8 \mathrm{GPa}$, the decompression data are similar to those of the compression ones. There are seven peaks that show negative slop between 8 and $12 \mathrm{GPa}\left(R_{2}, v_{4}, v_{2}, R_{4 c}, R_{4 f}, R_{4 g}\right.$ and $\left.R_{4 k}\right)$.

The discontinuity behaviors of each region are as the following: for Region $1\left(v_{1}\right.$ and $v_{3}$ modes), between 800 and $1100 \mathrm{~cm}^{-1}$, the slope of wavenumber vs. pressure $(d v / d P)$ is from 3.51-4.29 $\mathrm{cm}^{-1} / \mathrm{GPa}$ to $2.99-5.59 \mathrm{~cm}^{-1} / \mathrm{GPa}$. Some new peaks show the slope $(d v / d P)$ from 2.68 to $5.24 \mathrm{~cm}^{-1} / \mathrm{GPa}$. For Region 2, between 660 and $700 \mathrm{~cm}^{-1}$, the slope of wavenumber vs. pressure $(d v / d P)$ is from $2.68 \mathrm{~cm}^{-1} / \mathrm{GPa}$ to $1.32 \mathrm{~cm}^{-1} / \mathrm{GPa}$, but shows a negative trend between 8 and $12 \mathrm{GPa}$. For Region 3 ( $v_{2}$ and $v_{4}$ modes), between 420 to $660 \mathrm{~cm}^{-1}$, the slope of wavenumber vs. pressure $(d v / d P)$ is from $1.9-2.26 \mathrm{~cm}^{-1} / \mathrm{GPa}$ to $0.78-1.89 \mathrm{~cm}^{-1} / \mathrm{GPa}$, and two peaks show a negative slope between 8 and $12 \mathrm{GPa}$. For Region 4, below $420 \mathrm{~cm}^{-1}$, the slope of wavenumber vs. pressure $(d v / d P)$ is from $0.13-3.14 \mathrm{~cm}^{-1} / \mathrm{GPa}$ to $-0.93-2.44 \mathrm{~cm}^{-1} / \mathrm{GPa}$.

Table 1. Major Raman bands for scottyite on a previous experiment study and on this Raman spectroscopic study.

\begin{tabular}{|c|c|c|c|c|c|c|}
\hline $\begin{array}{l}\text { Major Raman } \\
\text { Bands }\end{array}$ & $\begin{array}{c}\nu_{1} \\
\text { Strong, Sharp; } \\
\mathrm{SiO}_{4} \text { Symmetric } \\
\text { Stretching }\end{array}$ & $\begin{array}{c}v_{2} \\
\text { Very Strong, } \\
\text { Sharp; } \\
\mathrm{SiO}_{4} \text { Symmetric } \\
\text { Bending }\end{array}$ & $\begin{array}{c}v_{3} \\
\text { Relatively } \\
\text { Weak; } \\
\mathrm{SiO}_{4} \\
\text { Anti-symmetric } \\
\text { Stretching }\end{array}$ & $\begin{array}{c}v_{4} \\
\text { Relatively } \\
\text { Strong, Sharp; } \\
\mathrm{SiO}_{4} \\
\text { Anti-Symmetric } \\
\text { Bending }\end{array}$ & $\begin{array}{c}R_{2}{ }^{1} \\
\text { Strong, Sharp; } \\
\text { Si-O-Si Bending } \\
\text { Mode }\end{array}$ & $\begin{array}{c}R_{4}{ }^{1} \\
\text { Strong to Weak; } \\
\mathrm{SiO}_{4} \\
\text { Rotational and } \\
\text { Translational } \\
\text { Modes }\end{array}$ \\
\hline Yang et al. [2] & 896 & 459 & $1019,958,866$ & $612,578,560$ & 675 & $<420$ \\
\hline This study & 895 & 458 & $1016,958,863$ & $608,579,560$ & 675 & $\begin{array}{c}358,315,303,243, \\
220,170,159,141, \\
120,86,75\end{array}$ \\
\hline
\end{tabular}

${ }^{1} R_{2}, R_{4}$ means second and fourth region on the Raman spectra of scottyite. 


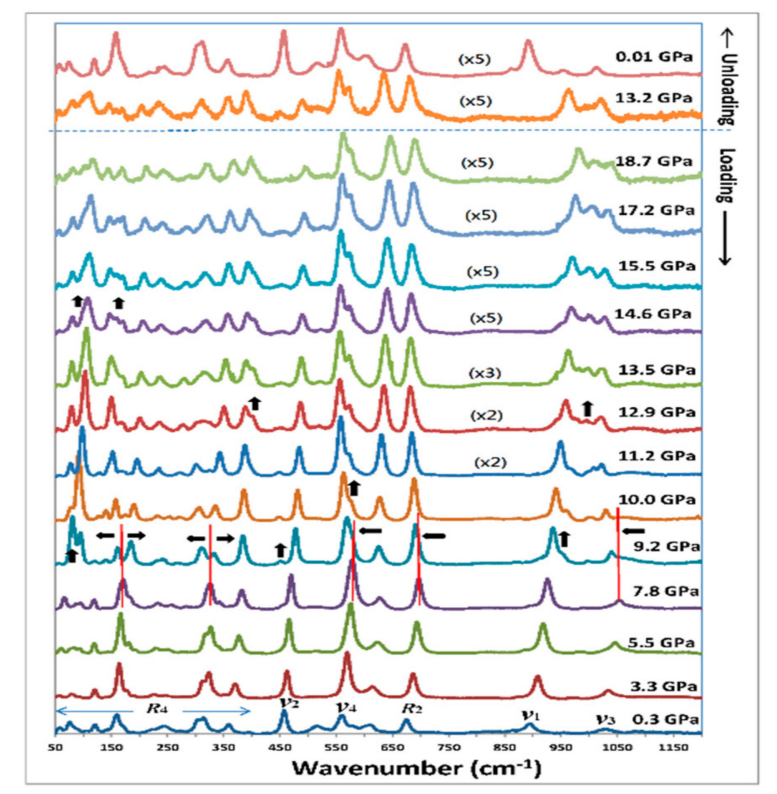

Figure 1. A series of Raman spectra of scottyite showing the effect of pressure on the Raman modes. The $v_{1}$ and $v_{4}$ mode is the more intense Raman modes in scottyite. The distinct peak (new peak) is marked "^". Arrows $(\leftarrow, \rightarrow)$ indicate the direction of peak movement.

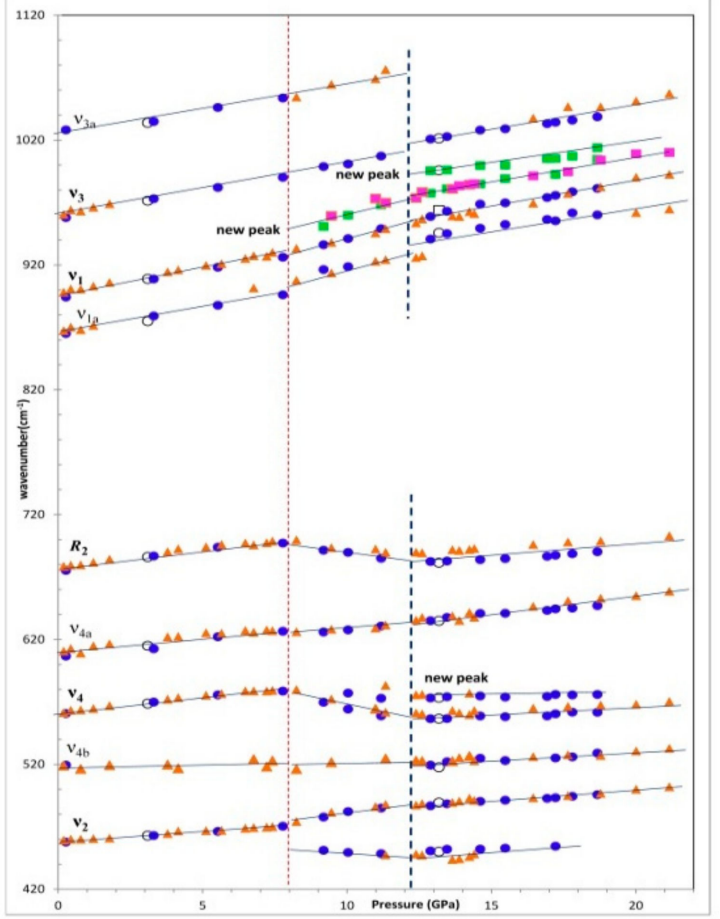

(a)

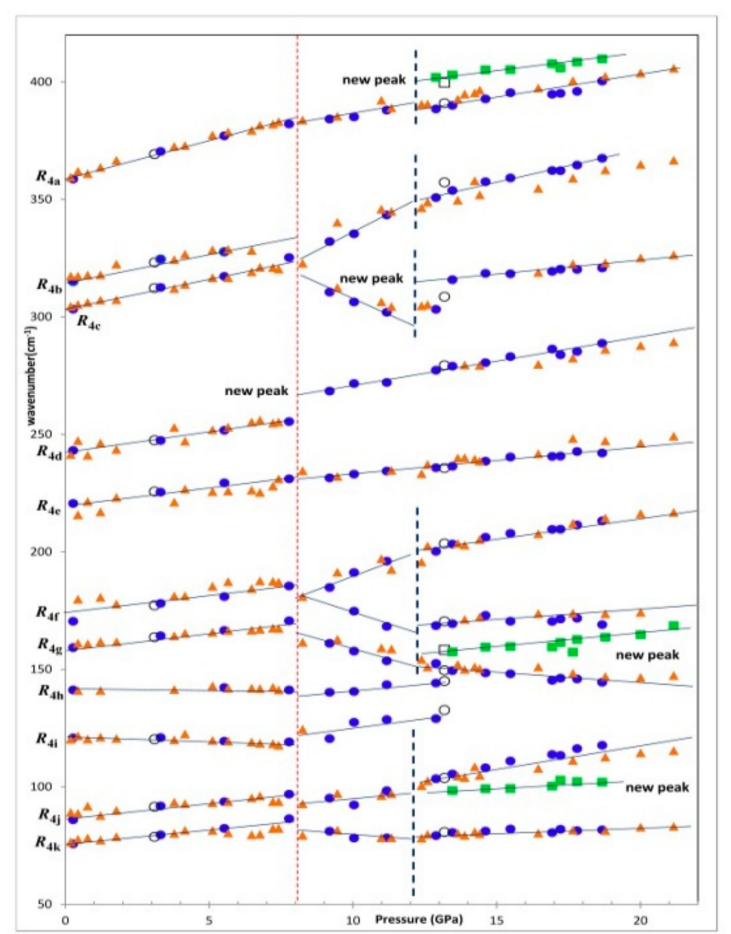

(b)

Figure 2. The variations in the wavenumber for each Raman mode of scottyite with pressure. (a) Wavenumber range: $420-1120 \mathrm{~cm}^{-1}$; (b) wavenumber range: $50-420 \mathrm{~cm}^{-1}$. Data for loading process are shown as solid symbols (two runs: red triangle and blue round shape) and those for unloading process as open symbols. The dotted line means the discontinuity of the slope on each Raman mode. There are some new peaks (green/pink square shape) during the loading process which are on $v_{1}, R_{4 d}$ modes between 8 and $12 \mathrm{GPa}$ and $R_{4 a}, R_{4 c}, R_{4 j}$ modes above $12 \mathrm{GPa}$. The solid lines are the eyeball linear fit of the data. 
Table 2. The variations in the slope $\left(d v / d P, \mathrm{~cm}^{-1} / \mathrm{GPa}\right)$ of each Raman mode in scottyite.

\begin{tabular}{|c|c|c|c|c|c|c|c|c|c|c|c|c|}
\hline \multirow{2}{*}{ Raman Mode } & \multicolumn{4}{|c|}{$v_{1}$} & \multicolumn{2}{|c|}{$v_{2}$} & \multicolumn{2}{|c|}{$v_{3}$} & \multicolumn{3}{|c|}{$v_{4}$} & \multirow{2}{*}{$\begin{array}{l}R_{2} \\
R_{2}\end{array}$} \\
\hline & $v_{1}$ & New & New & $v_{1 a}$ & $v_{2}$ & $v_{2 a}$ & $v_{3}$ & $v_{3 a}$ & $v_{4}$ & New & $v_{4 a}$ & \\
\hline$<8 \mathrm{GPa}$ slope & 4.27 & - & - & 4.12 & \multicolumn{2}{|c|}{1.90} & 4.28 & 3.51 & 2.26 & - & 2.09 & 2.68 \\
\hline 8-12 GPa slope & 5.59 & 5.24 & - & 4.09 & 3.57 & -1.33 & 4.29 & - & -4.68 & - & 2.44 & -3.35 \\
\hline$>12$ GPa slope & 3.62 & 3.97 & 2.68 & 3.35 & 1.56 & 0.78 & - & - & 1.25 & 1.12 & 1.89 & 1.32 \\
\hline
\end{tabular}

Table 3. The variations in the slope $\left(d v / d P, \mathrm{~cm}^{-1} / \mathrm{GPa}\right)$ of each Raman mode in scottyite.

\begin{tabular}{|c|c|c|c|c|c|c|c|c|c|c|c|c|c|c|c|c|c|c|}
\hline \multirow{3}{*}{ Raman Mode } & \multicolumn{18}{|c|}{$R_{4}$} \\
\hline & \multirow{2}{*}{ New } & \multirow{2}{*}{$a$} & \multirow{2}{*}{$b$} & \multicolumn{2}{|r|}{$c$} & \multirow{2}{*}{ New } & \multirow{2}{*}{$d$} & \multirow{2}{*}{ New } & \multirow{2}{*}{$e$} & \multicolumn{2}{|c|}{$f$} & \multicolumn{2}{|c|}{$g$} & \multirow{2}{*}{$h$} & \multirow{2}{*}{$i$} & \multicolumn{2}{|c|}{$j$} & \multirow{2}{*}{$k$} \\
\hline & & & & $c 1$ & $c 2$ & & & & & $f 1$ & $f 2$ & $g 1$ & $g^{2}$ & & & $j 1$ & $j 2$ & \\
\hline$<8$ GPa slope & - & 3.14 & 2.44 & \multicolumn{2}{|c|}{2.31} & - & 1.66 & - & 1.62 & \multicolumn{2}{|c|}{1.95} & \multirow{2}{*}{\multicolumn{2}{|c|}{$\begin{array}{c}1.48 \\
-3.72\end{array}$}} & 0.13 & 0.58 & \multirow{2}{*}{\multicolumn{2}{|c|}{$\begin{array}{l}0.96 \\
1.79\end{array}$}} & 0.57 \\
\hline 8-12 GPa slope & - & 1.94 & - & 5.78 & -4.27 & - & - & & 1.43 & 5.54 & -5.71 & & & 1.69 & 3.91 & & & -1.35 \\
\hline$>12$ GPa slope & 1.18 & 1.53 & - & 2.44 & - & 0.92 & - & 1.75 & 1.07 & 1.76 & 0.19 & -0.93 & 0.96 & - & - & 2.35 & 0.95 & 0.12 \\
\hline
\end{tabular}

\subsection{X-ray Diffraction Studies}

A series of X-Ray Diffraction patterns are overlain to show the structural changes with pressure in scottyite in Figure 3. Several new peaks were observed above $8 \mathrm{GPa}$, which indicates the transformation of scottyite to high-pressure phase (Figure 3). The variations in d-spacings of the diffraction peaks as a function of pressure for scottyite are plotted in Figure 4 . The calculated cell parameters, $a, b$ and $c$, with the change in pressure are plotted in Figure 5, and tabulated in Table 4.

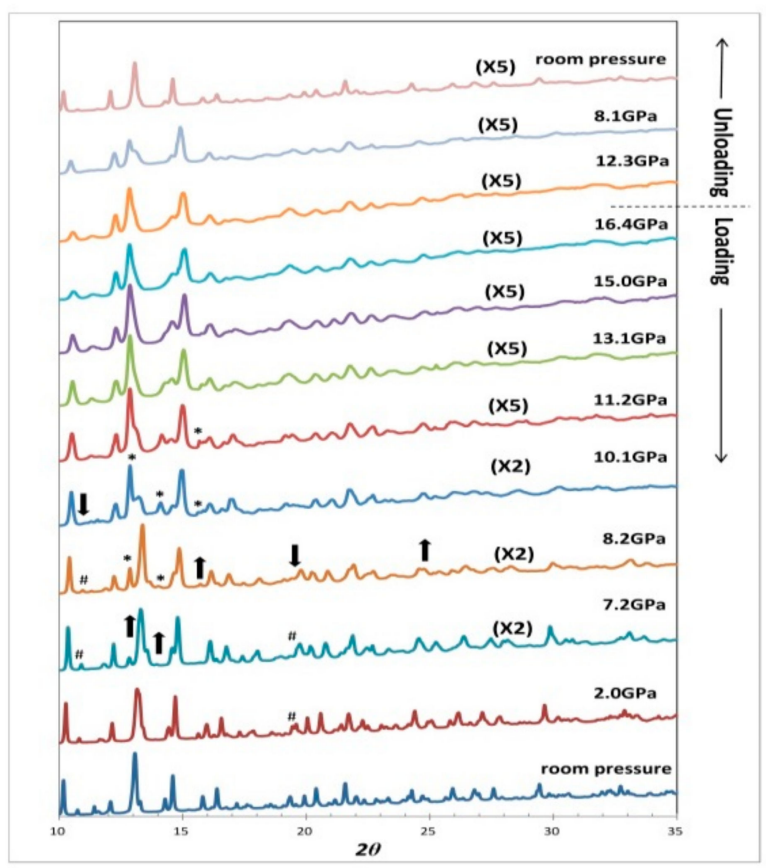

Figure 3. A series of X-Ray Diffraction patterns showing the sequences of phase transitions in scottyite during the loading and unloading processes. Scottyite exhibits four new peaks above 7-8 GPa (indicated by "^" and "*") suggesting the onset of phase transition. In addition, some peaks disappeared or merged (indicated by " $\downarrow$ " and "\#") when the pressure is over 10 GPa. The scottyite phase was recovered during the unloading process. 


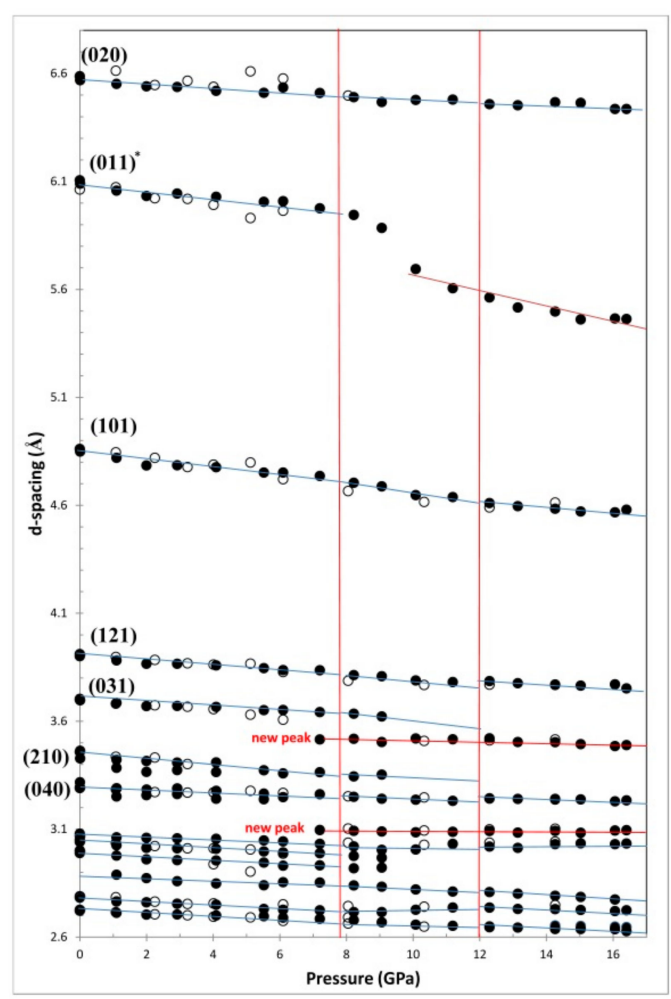

(a)

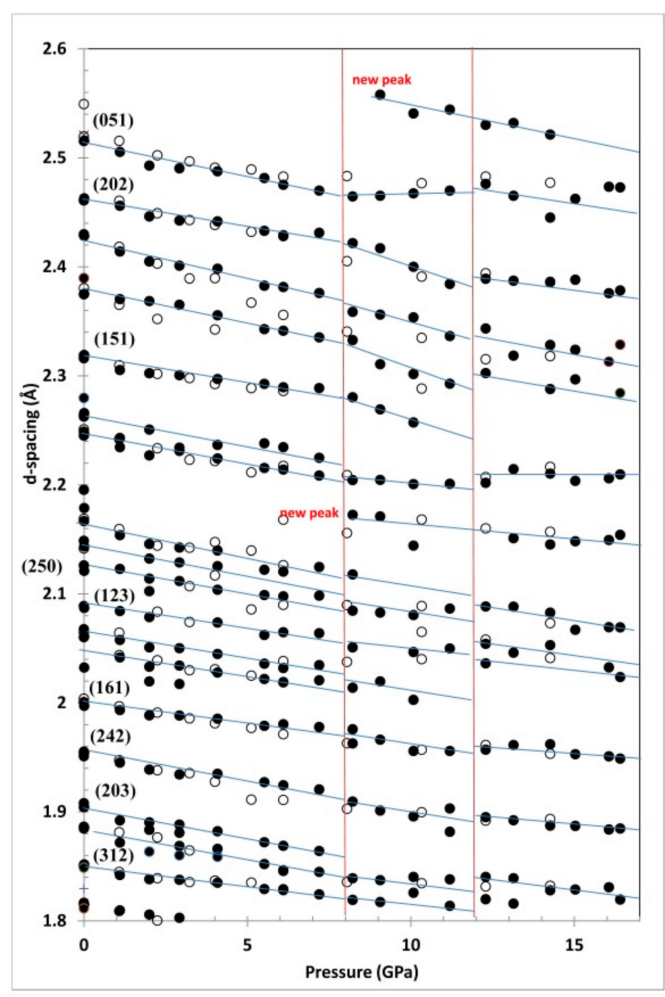

(b)

Figure 4. The variations in $d$-spacing for each diffraction peak in various phase of scottyite. (a) 2.6-6.8; (b) d-spacing range: 1.8-2.6. (*: Intensity weak, the trend is for reference only; solid circles: loading; open circles: unloading).

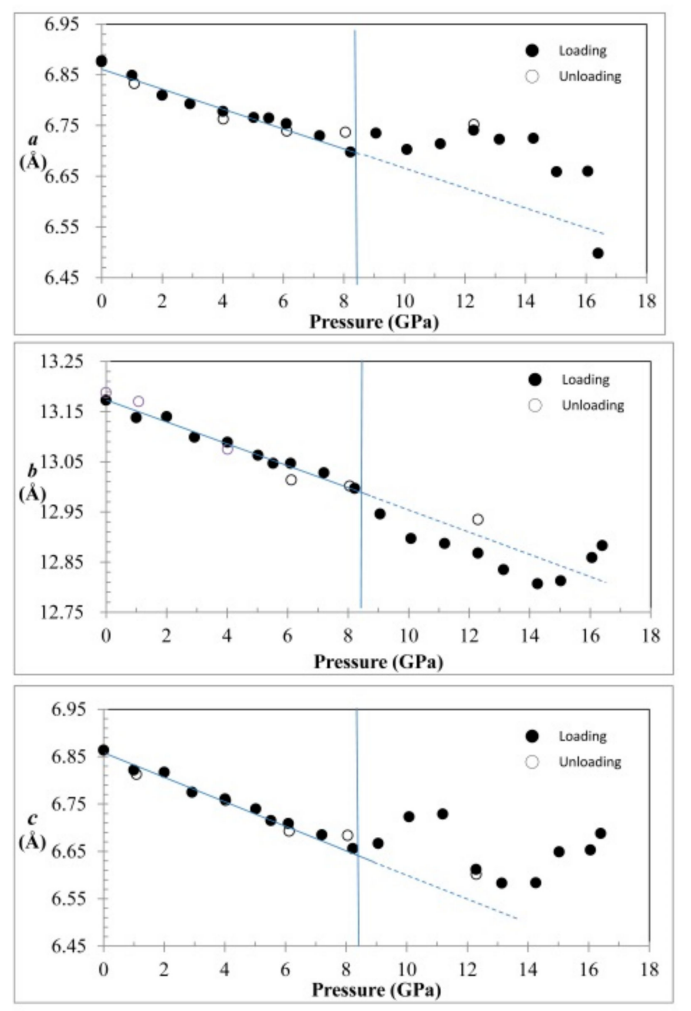

Figure 5. The compressibility of the lattice parameters $(a, b$ and $c)$ of scottyite with pressure up to 17 GPa (solid circles: loading; open circles: unloading). 
Table 4. The unit cell parameters, molar volume and their normalized ratios of scottyite in the loading and unloading processes.

\begin{tabular}{ccccccccc}
\hline Pressure (GPa) & $\boldsymbol{a}$ & $\boldsymbol{b}$ & $\boldsymbol{c}$ & $\boldsymbol{V}$ & $\boldsymbol{a} / \boldsymbol{a}_{\mathbf{0}}$ & $\boldsymbol{b} / \boldsymbol{b}_{\mathbf{0}}$ & $\boldsymbol{c} / \boldsymbol{c}_{\mathbf{0}}$ & $\boldsymbol{V} / \boldsymbol{V}_{\mathbf{0}}$ \\
\hline 0.01 & 6.876 & 13.173 & 6.864 & 621.72 & 1 & 1 & 1 & 1 \\
1.00 & 6.849 & 13.138 & 6.822 & 613.86 & 0.996 & 0.997 & 0.994 & 0.987 \\
2.00 & 6.81 & 13.140 & 6.817 & 610.01 & 0.990 & 0.997 & 0.993 & 0.981 \\
2.92 & 6.793 & 13.099 & 6.775 & 602.85 & 0.988 & 0.994 & 0.987 & 0.970 \\
4.01 & 6.778 & 13.089 & 6.761 & 599.82 & 0.986 & 0.994 & 0.985 & 0.965 \\
5.02 & 6.766 & 13.063 & 6.74 & 595.71 & 0.984 & 0.992 & 0.982 & 0.958 \\
5.52 & 6.765 & 13.047 & 6.715 & 592.69 & 0.984 & 0.990 & 0.978 & 0.953 \\
6.10 & 6.754 & 13.047 & 6.709 & 591.19 & 0.982 & 0.990 & 0.977 & 0.951 \\
7.20 & 6.730 & 13.028 & 6.685 & 586.13 & 0.979 & 0.989 & 0.974 & 0.943 \\
8.22 & 6.698 & 12.997 & 6.656 & 579.43 & 0.974 & 0.987 & 0.970 & 0.932 \\
9.06 & 6.735 & 12.946 & 6.667 & 581.30 & 0.979 & 0.983 & 0.971 & 0.935 \\
10.08 & 6.703 & 12.897 & 6.723 & 581.19 & 0.975 & 0.979 & 0.979 & 0.935 \\
11.19 & 6.714 & 12.887 & 6.729 & 582.22 & 0.976 & 0.978 & 0.980 & 0.936 \\
12.29 & 6.741 & 12.868 & 6.602 & 572.68 & 0.980 & 0.977 & 0.962 & 0.921 \\
13.14 & 6.723 & 12.835 & 6.583 & 568.05 & 0.978 & 0.974 & 0.959 & 0.914 \\
14.26 & 6.725 & 12.807 & 6.584 & 567.06 & 0.978 & 0.972 & 0.959 & 0.912 \\
15.03 & 6.659 & 12.813 & 6.649 & 567.30 & 0.968 & 0.973 & 0.969 & 0.912 \\
16.06 & 6.66 & 12.859 & 6.653 & 569.77 & 0.969 & 0.976 & 0.969 & 0.916 \\
16.40 & 6.498 & 12.883 & 6.688 & 559.88 & 0.945 & 0.978 & 0.974 & 0.901 \\
& & & Unloading & & & & \\
12.29 & 6.752 & 12.935 & 6.612 & 577.47 & 0.982 & 0.982 & 0.963 & 0.929 \\
8.05 & 6.737 & 13.002 & 6.684 & 585.48 & 0.980 & 0.987 & 0.974 & 0.942 \\
6.12 & 6.739 & 13.014 & 6.693 & 586.99 & 0.980 & 0.988 & 0.975 & 0.944 \\
4.02 & 6.763 & 13.075 & 6.758 & 597.58 & 0.984 & 0.993 & 0.985 & 0.961 \\
1.08 & 6.833 & 13.170 & 6.813 & 613.11 & 0.994 & 1.000 & 0.993 & 0.986 \\
0.01 & 6.878 & 13.188 & 6.864 & 622.61 & 1.000 & 1.001 & 1.000 & 1.001 \\
\hline
\end{tabular}

At first glance, the diffraction patterns of scottyite shown in Figure 3 do not seem to show a very significant change with pressure. However, closer examination of these patterns reveals some minor changes during the compression process. With an increase in pressure, we observed that four new diffraction peaks show up near $8 \mathrm{GPa}$. Figures 3 and $4 \mathrm{a}, \mathrm{b}$ display four new peaks in the intervals between (031) and (210); (040) and (102); near (051) and (250) diffractive planes, the d-spacing of which is near 3.5, 3.1, 2.6 and $2.2 \AA$, respectively, above $8 \mathrm{GPa}$. Some peaks either disappear or were merged with other peaks when the pressure was over $10 \mathrm{GPa}$, such as (031), (210), (201), (022), (151) and (321) diffractive planes. The appearance of more diffraction peaks implies that the high-pressure phase of scottyite has a lower symmetry.

The variations in $a / a_{0}, b / b_{0}, c / c_{0}$ and molar volume with pressure for scottyite are listed in Table 4. The compression data are fitted to the Birch-Murnaghan equation (Equation (1)).

$$
\mathrm{P}=\frac{3}{2} K o\left[(\mathrm{Vo} / \mathrm{V})^{7 / 3}-(\mathrm{Vo} / \mathrm{V})^{5 / 3}\right]\left\{1-\frac{3}{4}\left(4-K o^{\prime}\right)\left[(\mathrm{Vo} / \mathrm{V})^{2 / 3}-1\right]\right\}
$$

We obtain a bulk modulus $\left(K_{o}\right)$ value of scottyite as $102 \pm 5 \mathrm{GPa}$ (assuming that $K_{o}{ }^{\prime}$ is 4) (Figure 6). 


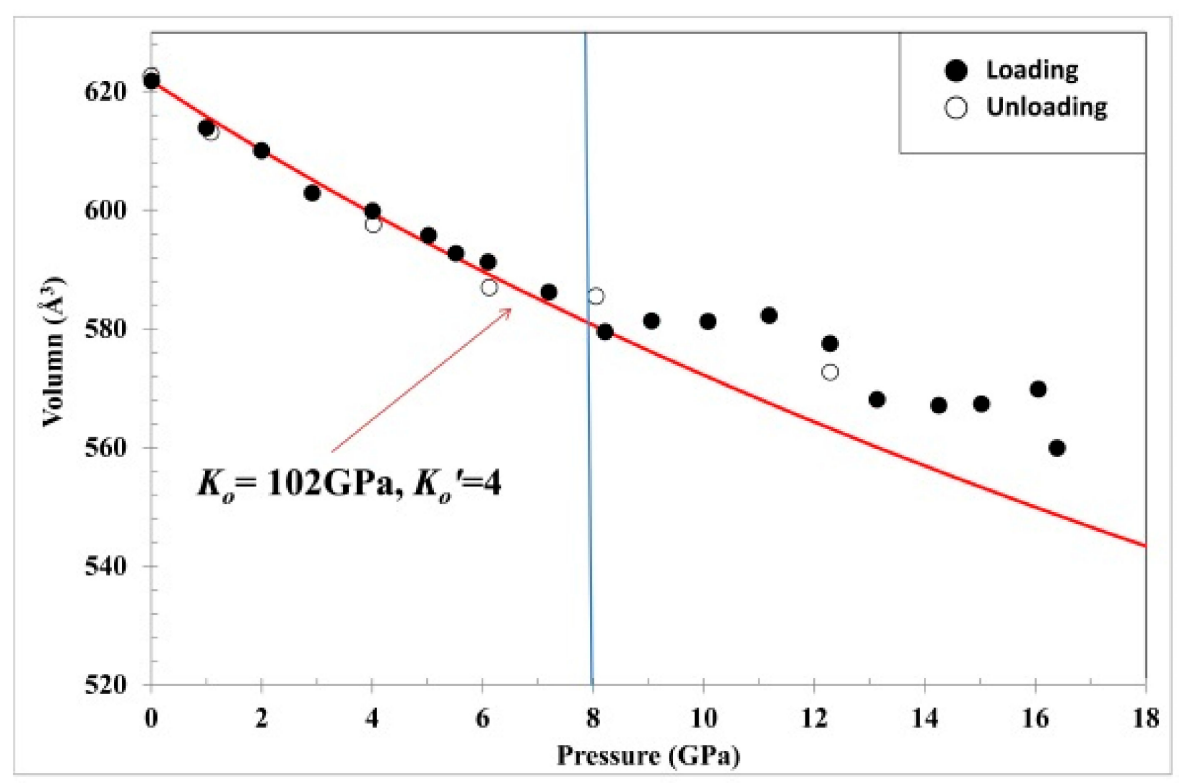

Figure 6. The compression data as fitted to the Birch-Murnaghan equation, to give a bulk modulus, $K_{o}$, of $102 \mathrm{GPa}$, assuming $K_{o}{ }^{\prime}=4$. Above $8 \mathrm{GPa}$, (assuming that the structure remains unchanged) it is clearly seen that all the data deviate from the compression curve.

\section{Discussion}

\subsection{Anisotropic Compressibility}

We found that the $c$-axis was the most compressible axis in scottyite, the $b$-axis was the least, and the $a$-axis was similar to the $c$-axis on the compression (Figure 5 and Table 4). The scottyite structure is based on a tetrahedral framework consisting of $\mathrm{SiO}_{4}$ and $\mathrm{CuO}_{4}$ tetrahedrons. The $\mathrm{CuO}_{4}$ tetrahedrons are considerably flattened, and they share corners to form chains parallel to the $c$-axis. The chains are interlinked by the $\mathrm{Si}_{2} \mathrm{O}_{7}$ dimers oriented parallel to the $b$-axis. $[2,6,7]$ The largest bond distance of $\mathrm{M}-\mathrm{O}$ was $\mathrm{Ba}-\mathrm{O}(2.825 \AA)$ where $\mathrm{Ba}^{2+}$ cations are in the framework channels. The $\mathrm{SiO}_{4}$ is a rigid body and is linked to the $\mathrm{Si}_{2} \mathrm{O}_{7}$ dimer, so it is hard to compress. However, $\mathrm{CuO}_{4}$ tetrahedron layers are parallel to the $a c$-plane, thus making the $a$-axis and $c$-axis relatively easy to compress.

\subsection{The Pressure of the Phase Transition}

The four new peaks in the diffraction patterns and the discontinuities in the slopes of $d$ spacing versus pressure plot all occurred at approximately 7-8 GPa, which is quite distinct for scottyite. Figure 5 shows the variations in the $a-, b$ - and $c$-parameters of scottyite with pressure, assuming that the scottyite structure remains during the loading and unloading processes. From Figure 5, we observed a kink in their compression curves at about $8 \mathrm{GPa}$ in all three crystallographic axes. Above $9 \mathrm{GPa}$, the lattice parameters behave in a less compressible way, and show larger values than those extrapolated from the low pressures, which is not reasonable. The offset of the lattice parameters on the $a$-axes and $c$-axes direction is similar. All the lattice parameters are reversible under the unloading process. The deviation from the normal compression behavior in scottyite is more clearly seen in Figure 6. Below $8 \mathrm{GPa}$, the compression data can be fitted to a bulk modulus of $102 \mathrm{GPa}$ with $K_{o}{ }^{\prime}=4$ by the Birch-Murnaghan equation (Equation (1)), but the data show a large deviation from the normal compression curve above $8 \mathrm{GPa}$. Some XRD peaks disappeared or merged with other peaks when the pressure exceeded $10 \mathrm{GPa}$.

In addition, we also found the discontinuities of each Raman mode in the $d v / d P$ plot at near $8 \mathrm{GPa}$, and some Raman modes showed negative slop of $d v / d P$ between 8 and $12 \mathrm{GPa}$. Most of the trend with the negative slop of $d v / d P$ belonged to $R_{2}$ (Si-O-Si bending mode), $v_{4}\left(\mathrm{SiO}_{4}\right.$ anti-symmetric bending $)$ and $v_{2}\left(\mathrm{SiO}_{4}\right.$ symmetric bending) which deserves further investigation in order to understand the mechanism of the phase transition. We 
conclude that scottyite has encountered a structural phase transition at $8 \mathrm{GPa}$ and the transition is reversible.

\subsection{Post-Scottyite Structure Analysis}

Preliminary high-pressure Raman and X-ray investigation provided evidence that a reversible phase transition takes place at $8 \mathrm{GPa}$ in scottyite. We have tried to analyze the post-scottyite structure with GSAS-II program [13], and the most suitable candidate for the high pressure phase is maybe the monoclinic system of the Bravais lattice $\mathrm{C} 2 / \mathrm{m}$, with unit-cell parameters of $a=5.67 \AA, b=5.12 \AA, c=18.58 \AA, \beta=91.64^{\circ}$ and molar volume of $\mathrm{V}=539.3 \AA^{3}$ at $11.19 \mathrm{GPa}$. The fitting pattern is shown in Figure 7 . However, since there are still many peaks that cannot be matched, the structure that we proposed above may need further experimental data and analysis to justify it.

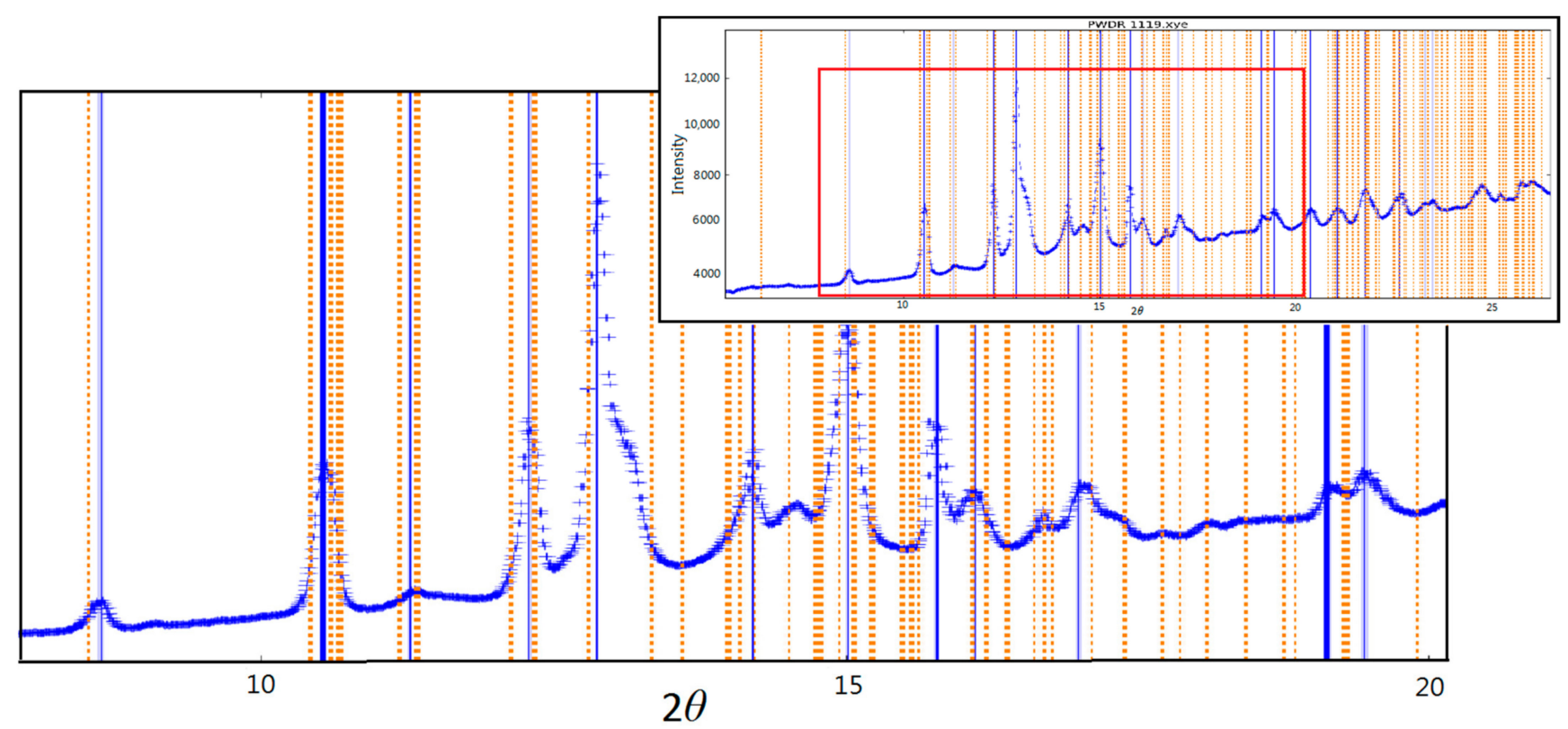

Figure 7. Comparison of the XRD pattern at $11.19 \mathrm{GPa}$ with the diffraction peaks of candidate high-pressure phase obtained by GSAS-II. The blue lines are the XRD peak positions at $11.19 \mathrm{GPa}$ and the orange lines are the diffraction peaks obtained by GSAS-II. The inserted figure is the entire diffraction pattern.

A comparison of crystallographic data of $\mathrm{BaM}_{2} \mathrm{Si}_{2} \mathrm{O}_{7}$-type $(\mathrm{M}=\mathrm{Be}, \mathrm{Mg}, \mathrm{Mn}, \mathrm{Fe}, \mathrm{Co}$, $\mathrm{Zn}$, and $\mathrm{Cu}$ ) minerals [2,14-18] shows that the structure with the monoclinic system is $\mathrm{M}=\mathrm{Mg}, \mathrm{Mn}, \mathrm{Fe}, \mathrm{Co}$, and $\mathrm{Zn}$. There is a strong resemblance among them in the structure (Table 5). The radius of $\mathrm{Cu}^{2+}$ is similar to $\mathrm{Mg}^{2+}, \mathrm{Co}^{2+}$ and $\mathrm{Zn}^{2+}$, so we speculate that the post-scottyite phase may be similar among these compounds. However, this still needs to be verified by a single-crystal X-ray diffraction experiment.

Table 5. The crystal structure of some $\mathrm{BaM}_{2} \mathrm{Si}_{2} \mathrm{O}_{7}$-type minerals with the monoclinic system.

\begin{tabular}{|c|c|c|c|c|c|c|}
\hline \multirow{2}{*}{ Chemical Formula } & \multirow{2}{*}{$\begin{array}{l}\text { Space } \\
\text { Group }\end{array}$} & \multicolumn{4}{|c|}{ Unit-Cell Parameters } & \multirow[t]{2}{*}{ Si-O-Si $\left({ }^{\circ}\right)$} \\
\hline & & $a$ & $b$ & $c$ & $\beta$ & \\
\hline $\mathrm{BaFe}_{2} \mathrm{Si}_{2} \mathrm{O}_{7}$ [14] & $P 2_{1} / c$ & 7.488 & 13.785 & 7.085 & 118.23 & 127.2 \\
\hline $\mathrm{BaCo}_{2} \mathrm{Si}_{2} \mathrm{O}_{7}$ [15] & $\mathrm{C} 2 / \mathrm{c}$ & 7.213 & 12.781 & 13.762 & 90.299 & 124.5 \\
\hline $\mathrm{BaMg}_{2} \mathrm{Si}_{2} \mathrm{O}_{7}$ [16] & $\mathrm{C} 2 / \mathrm{c}$ & 7.246 & 12.714 & 13.748 & 90.211 & 125.2 \\
\hline $\mathrm{BaMn}_{2} \mathrm{Si}_{2} \mathrm{O}_{7}[17]$ & $\mathrm{C} 2 / \mathrm{c}$ & 7.295 & 12.963 & 14.032 & 90.248 & no data \\
\hline $\mathrm{BaZn}_{2} \mathrm{Si}_{2} \mathrm{O}_{7}-25^{\circ} \mathrm{C}[18]$ & $\mathrm{C} 2 / \mathrm{c}$ & 7.278 & 12.801 & 13.687 & 90.093 & 124.8 \\
\hline
\end{tabular}

From the Table 5, we know that the angle of Si-O-Si in the monoclinic $\mathrm{BaM}_{2} \mathrm{Si}_{2} \mathrm{O}_{7}$-type structure is between $124.5^{\circ}$ and $127.2^{\circ}$, which is smaller than in the scottyite structure 
(134.3 [2]). In other words, the compression deformation of the scottyite crystal maybe mainly occurs in Si-O-Si linkage formation, and thus results in $\mathrm{CuO}_{4}$ tetrahedra layer were compressed and adjusted. This then makes the $a$-axis and $c$-axis directions the most to be compressed.

The compression behavior of scottyite may be applied to silicates of similar structure, which is of significant meaning in the understanding of bonding characteristics of sorosilicates. Despite the fact that the structure of the post-scottyite phase has not been solved in this study, it is feasible that detailed single crystal XRD experiments in the future will help to resolve it.

Author Contributions: Conceptualization, P.-L.L.; Data curation, P.-L.L. and E.H.; Formal analysis, P.-L.L. and J.K.; Funding acquisition, P.-L.L. and J.K.; Project administration, P.-L.L.; Writing—original draft, P.-L.L. and E.H.; Writing—review \& editing, P.-L.L., E. Huang and J.K. All authors have read and agreed to the published version of the manuscript.

Funding: This project was supported by the Ministry of Science and Technology (MOST) (MOST106-2116-M-415-002). The installation of Raman spectroscope was funded by the Ministry of Science and Technology, grant numbers MOST 105-2116-M-006-019 to J.K., and partially supported by the grants from the "Core Facility Center", National Cheng Kung University, and "Geochemical Precious Instrument Platform Project: Southern Branch Ministry of Science.

Data Availability Statement: Not applicable.

Acknowledgments: We wish to thank J. Kung's and Yongjae lee's laboratories (Yonsei University, South Korea) for their technical support in this study during the experiments at Department of Earth Sciences, National Cheng Kung University, ROC and the Pohang Accelerator Laboratory, South Korea, respectively. Our thanks are also due to Bob Downs and Hexiong Yang for information regarding the origin of scottyite specimens (RRUFF Project, University of Arizona).

Conflicts of Interest: The authors declare no conflict of interest. The funders had no role in the design of the study; in the collection, analyses, or interpretation of data; in the writing of the manuscript, or in the decision to publish the results.

\section{References}

1. Durben, D.J; Mcmillan, P.F.; Wolf, G.H. Raman study of the high-pressure behavior of forsterite $\left(\mathrm{Mg}_{2} \mathrm{SiO}_{4}\right)$ crystal and glass. $A m$. Mineral. 1993, 78, 1143-1148.

2. Yang, H.; Downs, R.T.; Evans, S.H.; Pinch, W.W. Scottyite, the natural analog of synthetic $\mathrm{BaCu}_{2} \mathrm{Si}_{2} \mathrm{O}_{7}$, a new mineral from the Wessels mine, Kalahari Manganese Fields, South Africa. Am. Mineral. 2013, 98, 478-484. [CrossRef]

3. Hentschel, G. Die Lavaströme der Graulai: Eine neue Fundstelle in der Westeifel. Lapis 1993, 12, 11-23. (In German)

4. Blass, G.; Graf, H.-W.; Kolitsch, U.; Sebold, D. The new finds from the volcanic Eifel (II). Miner. Welt 2009, 20, 38-49. (In German)

5. Blass, G.; Schüller, W. “Unglaubliche” Kupfermineralien aus der Vulkaneifel: Auf'm Kopp bei Neroth. Lapis 2011, 36, 21-28. (In German)

6. Janczak, J.; Kubiak, R.; Glowiak, T. Structure of barium copper pyrosilicate at 300 K. Acta Crystallogr. 1990, C46, 1383-1385. [CrossRef]

7. Yamada, T.; Hiroi, Z.; Takano, M. Spin-1/2 quantum antiferromagnetic chains with tunable super exchange interactions found in $\mathrm{BaCu}_{2}\left(\mathrm{Si}_{1-\mathrm{x}} \mathrm{Ge}_{\mathrm{x}}\right)_{2} \mathrm{O}_{7}$. J. Solid State Chem. 2001, 156, 101-109. [CrossRef]

8. Yamada, T.; Takano, M.; Hiroi, Z. Spin-1/2 quantum antiferromagnetic chains with adjustable super exchange interactions found in $\mathrm{BaCu}_{2}\left(\mathrm{Si}_{1-\mathrm{x}} \mathrm{Ge}_{\mathrm{x}}\right)_{2} \mathrm{O}_{7}$. J. Alloys Compd. 2001, 317-318, 171-176. [CrossRef]

9. Shapenkov, S.V.; Zolotarev, A.A., Jr.; Zhitova, E.S.; Krivovichev, S.V.; Krzhizhanovskaya, M.G. High-temperature behavior of synthetic analogues of scottyite $\mathrm{BaCu}_{2} \mathrm{Si}_{2} \mathrm{O}_{7}$ and colinowensite $\mathrm{BaCuSi}_{2} \mathrm{O}_{6}$. Zap. RMO 2017, 146, 125-134.

10. Mao, H.K.; Xu, J.; Bell, P.M. Calibration of the ruby pressure gauge to 800 kbar under quasi-hydrostatic conditions. J. Geophys. Res. 1986, 91, 4673-4676. [CrossRef]

11. Hammersley, A.P.; Svensson, S.O.; Hanfland, M.; Fitch, A.N.; Häusermann, D. Two-Dimensional Detector Software: From Real Detector to Idealised Image or Two-Theta Scan. High Press. Res. 1996, 14, 235-248. [CrossRef]

12. Novak, G.A.; Colville, A.A. A practical interactive least-squares cell-parameter program using an electronic spreadsheet and a personal computer. Am. Mineral. 1989, 74, 488-490.

13. Toby, B.H.; Von Dreele, R.B. GSAS-II: The genesis of a modern open-source all purpose crystallography software package. J. Appl. Crystallogr. 2013, 46, 544-549. [CrossRef]

14. Cannillo, E.; Mazzi, F.; Rossi, G. Crystal structure of andremeyerite, $\mathrm{BaFe}(\mathrm{Fe}, \mathrm{Mn}, \mathrm{Mg}) \mathrm{Si}_{2} \mathrm{O}_{7}$. Am. Mineral. 1988, 73, 608-612. 
15. Adams, R.D.; Layland, R. Syntheses, structural analyses, and unusual magnetic properties of $\mathrm{Ba}_{2} \mathrm{CoSi}_{2} \mathrm{O}_{7}$ and $\mathrm{BaCo}_{2} \mathrm{Si}_{2} \mathrm{O}_{7}$. Inorg. Chem. 1996, 35, 3492-3497. [CrossRef]

16. Park, C.-H.; Choi, Y.-N. Crystal structure of $\mathrm{BaMg}_{2} \mathrm{Si}_{2} \mathrm{O}_{7}$ and $\mathrm{Eu}^{2+}$ luminescence. J. Solid State Chem. 2009, 182, 1884-1888. [CrossRef]

17. Lu, G.X.; Yang, L.Q.; Lin, J.H. One-dimensional magnetic interaction in $\mathrm{BaMn}_{2} \mathrm{Si}_{2} \mathrm{O}_{7}$. Solid State Commun. 2000, 114, 113-116. [CrossRef]

18. Lin, J.H.; Lu, G.X.; Du, J.; Su, M.Z.; Loong, C.-K.; Richardson, J.W., Jr. Phase transition and crystal structures of BaZn ${ }_{2} \mathrm{Si}_{2} \mathrm{O}_{7} . J$. Phys. Chem. Solids 1999, 60, 975-983. [CrossRef] 